\title{
Macaque model of in situ thromboembolic stroke
}

\section{Wateau $0 .{ }^{1,2}$, Orset C. ${ }^{2}$, Vivien $D_{0}{ }^{2}$, Contamin $H_{0}{ }^{1}$, Canet-Soulas $E_{0}{ }^{3}$, Verset M. ${ }^{1}$, Agin V. ${ }^{2}$}

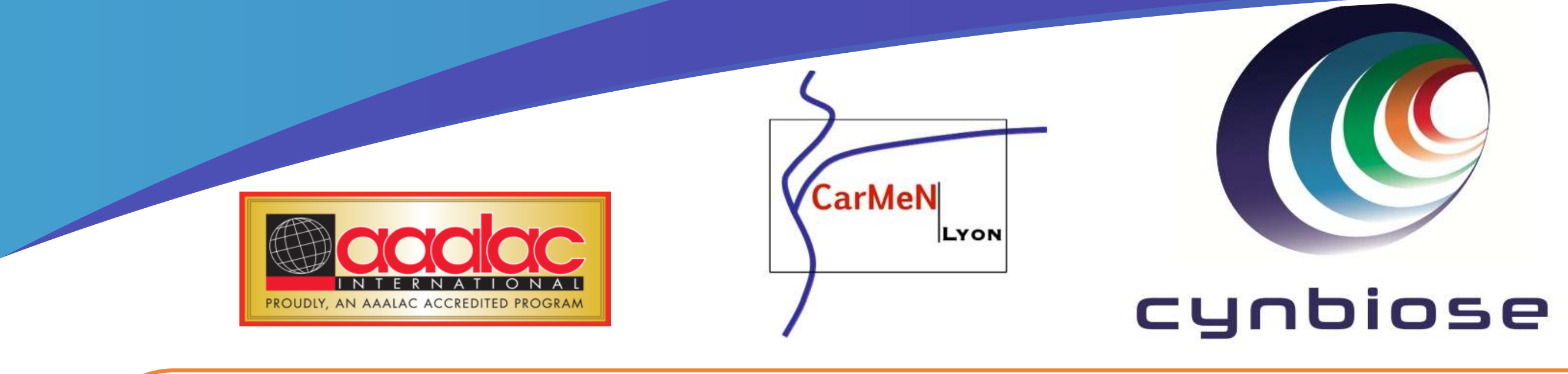

\section{INTRODUCTION}

$\checkmark$ Stroke is the third leading cause of mortality and the first cause of handicap in the world.

$\checkmark$ Novel insights into the pathophysiology of the neurovascular unit after stroke call for the use of new strategies to improve stroke treatment.

$\checkmark$ Unfortunately, despite the plethora of drugs that display clear beneficial effects in animal models of experimental ischemia, their subsequent use in clinical trials has been disappointing. As such, one is forced to consider that new animal models of focal cerebral ischemia may be required before translation to clinical trials.

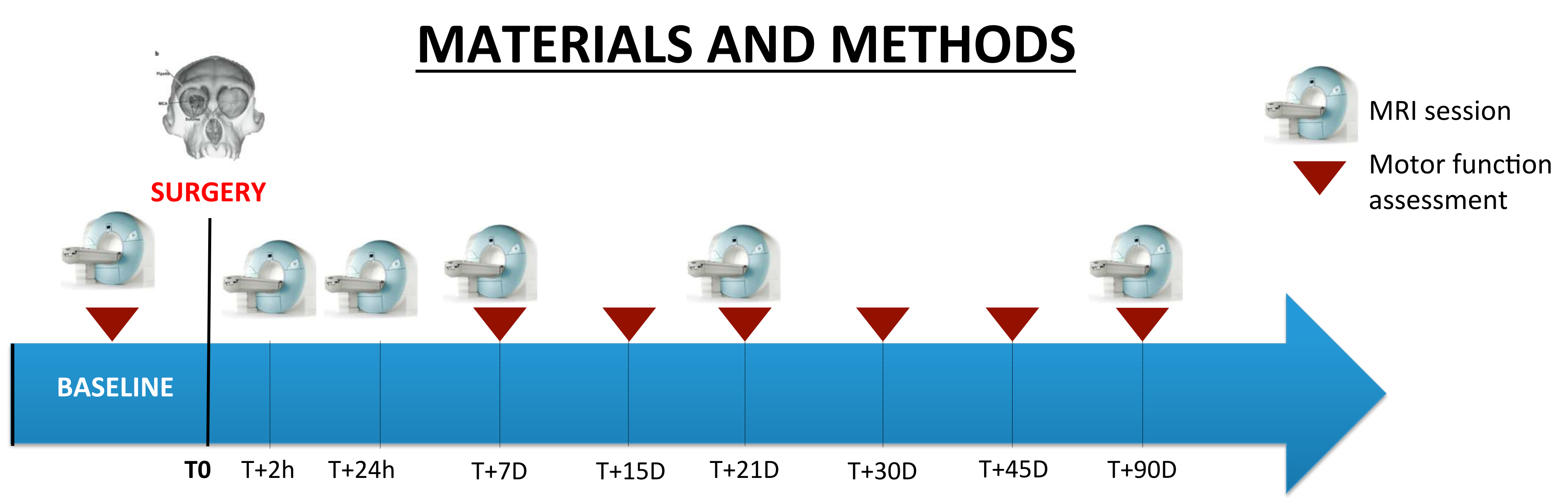

$\mathcal{J}$ In situ microinjection of thrombin is used to trigger a local clot formation in the middle cerebral artery of adult male rhesus monkeys.
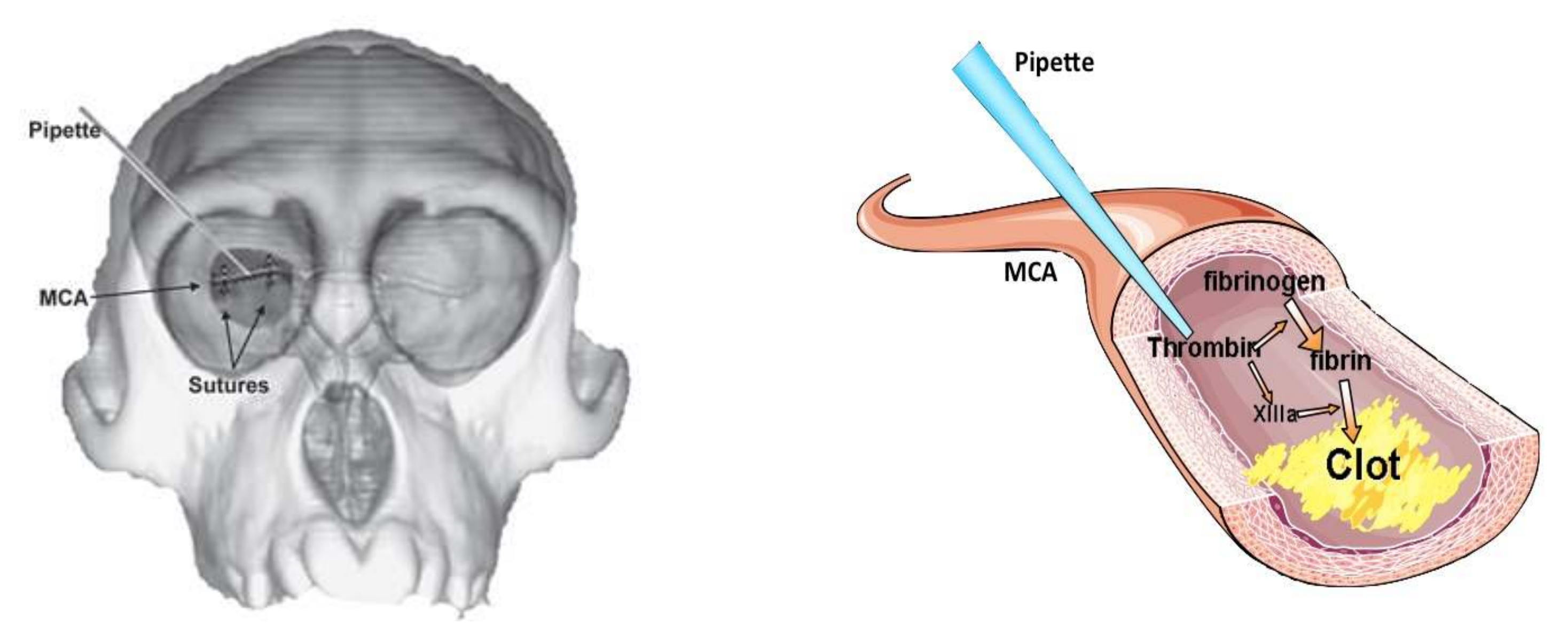

$\checkmark$ Animals are submitted to MRI (3T) analyses including:

$\diamond$ Angiography (3D TOF),

$\diamond \mathrm{T} 2$,

$\diamond$ FLAIR,

$\diamond$ Diffusion (DWI),

$\diamond \mathrm{T} 1$ pre-contrast

$\diamond$ Perfusion (PWI)

$\diamond \mathrm{T} 1$ post-contrast

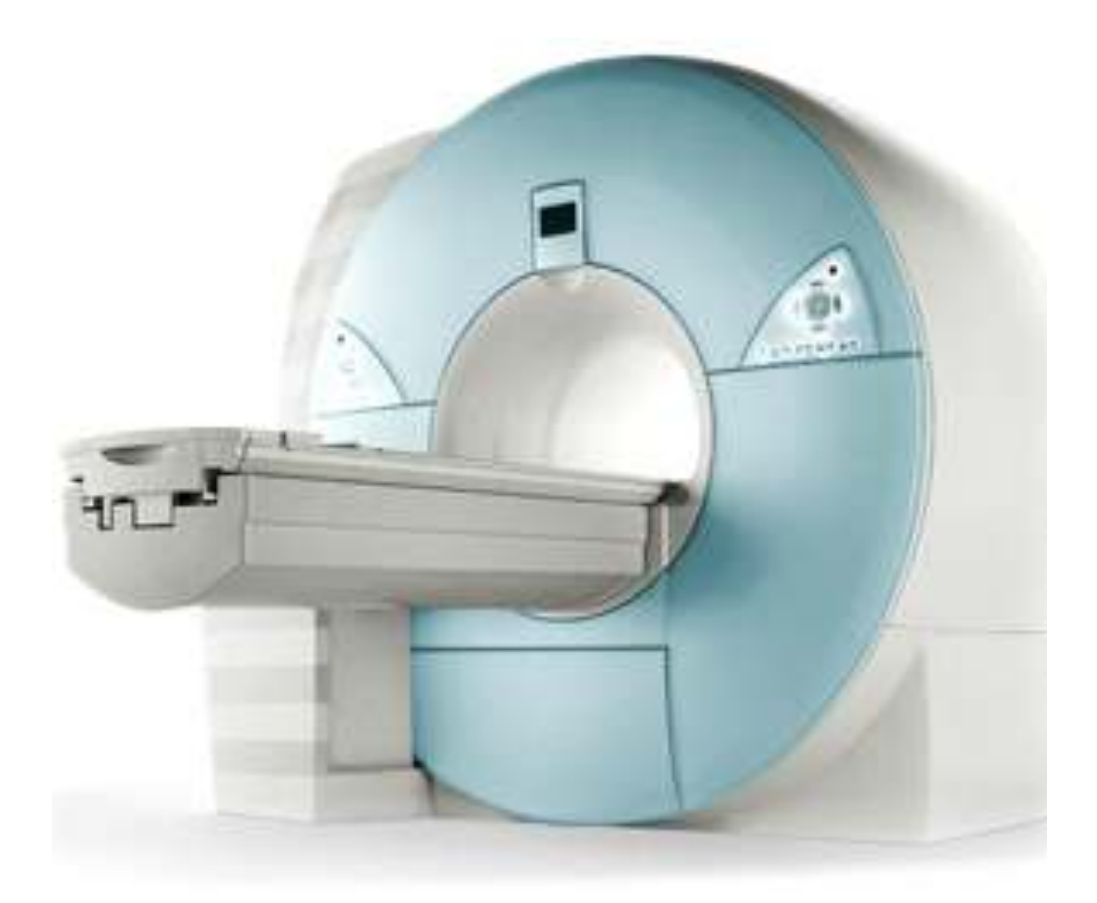

$\checkmark \mathrm{MRI}$ is performed before and at $2 \mathrm{~h}, 24 \mathrm{~h}, 7$ days, 15 days and 90 days after stroke onset.

$\checkmark$ Motor function assessment, particularly manual dexterity and digit strength, is performed over the 3-months period post-stroke by using an adaptation of the hand dexterity task (Moore et al., 2010).

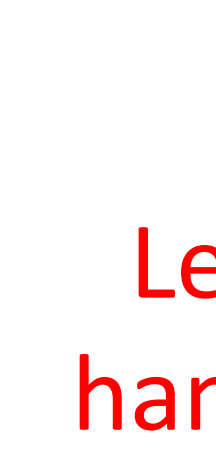

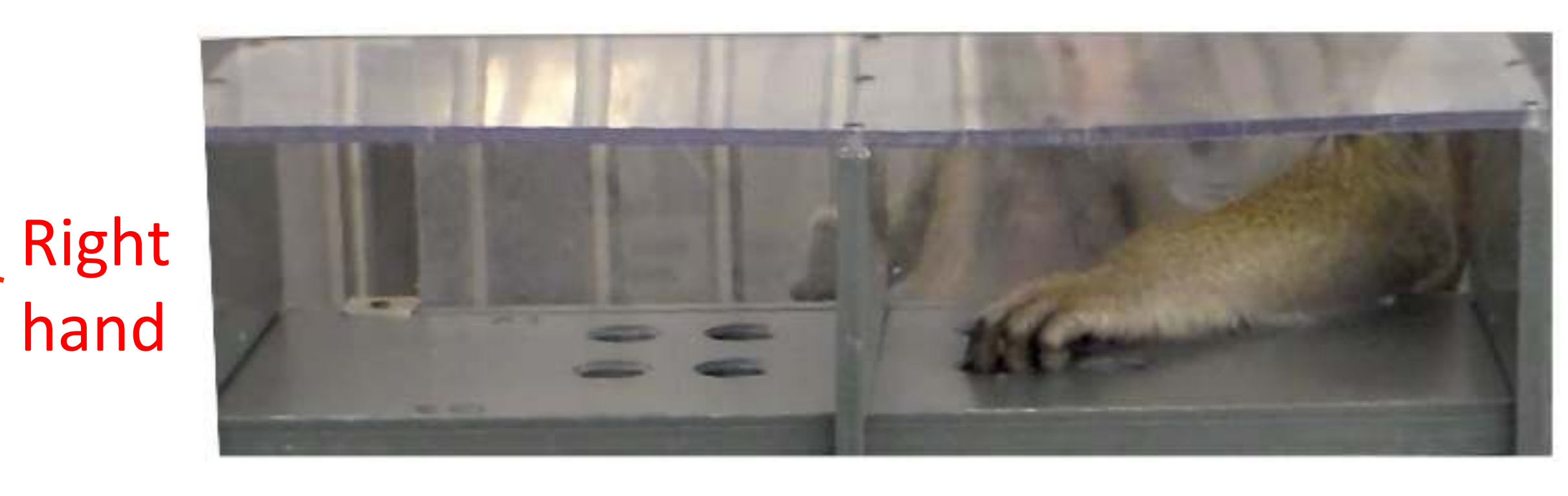

REFERENCES $\checkmark$ Orset et al., Mouse Model of In Situ Thromboembolic Stroke and Reperfusion. Stroke. 2007

$\checkmark$ Moore et al., Assessment of motor function of the hand in aged rhesus monkeys. Somatosens Mot Res. 2010

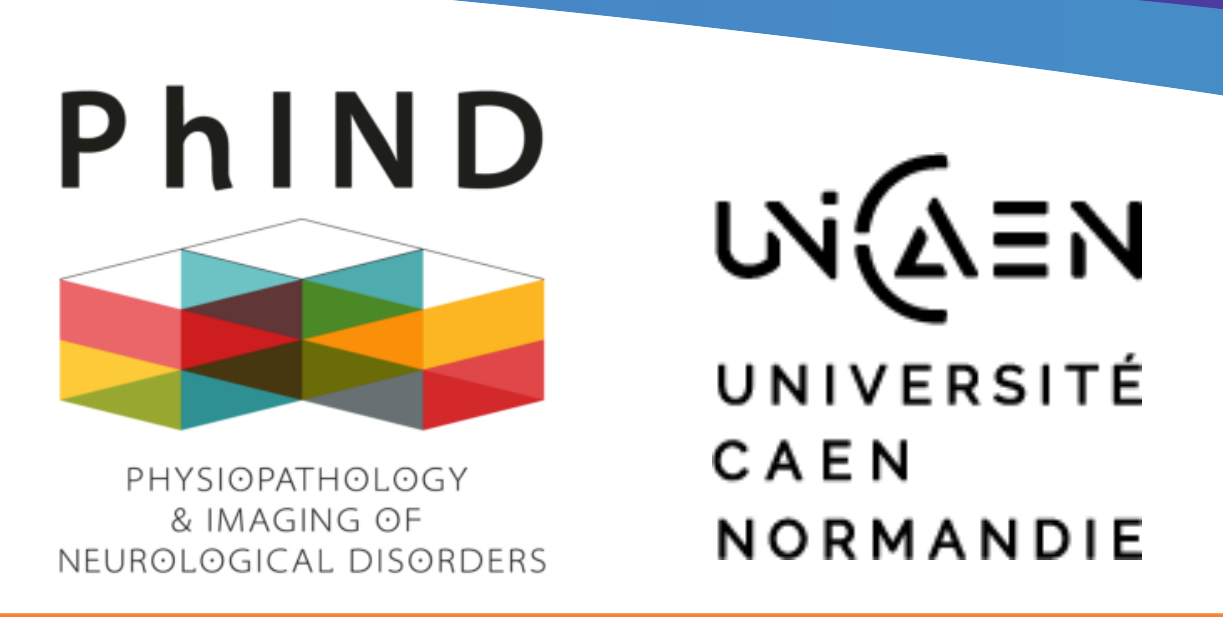

\section{RESULTS}

$\checkmark$ Motor function assessment:
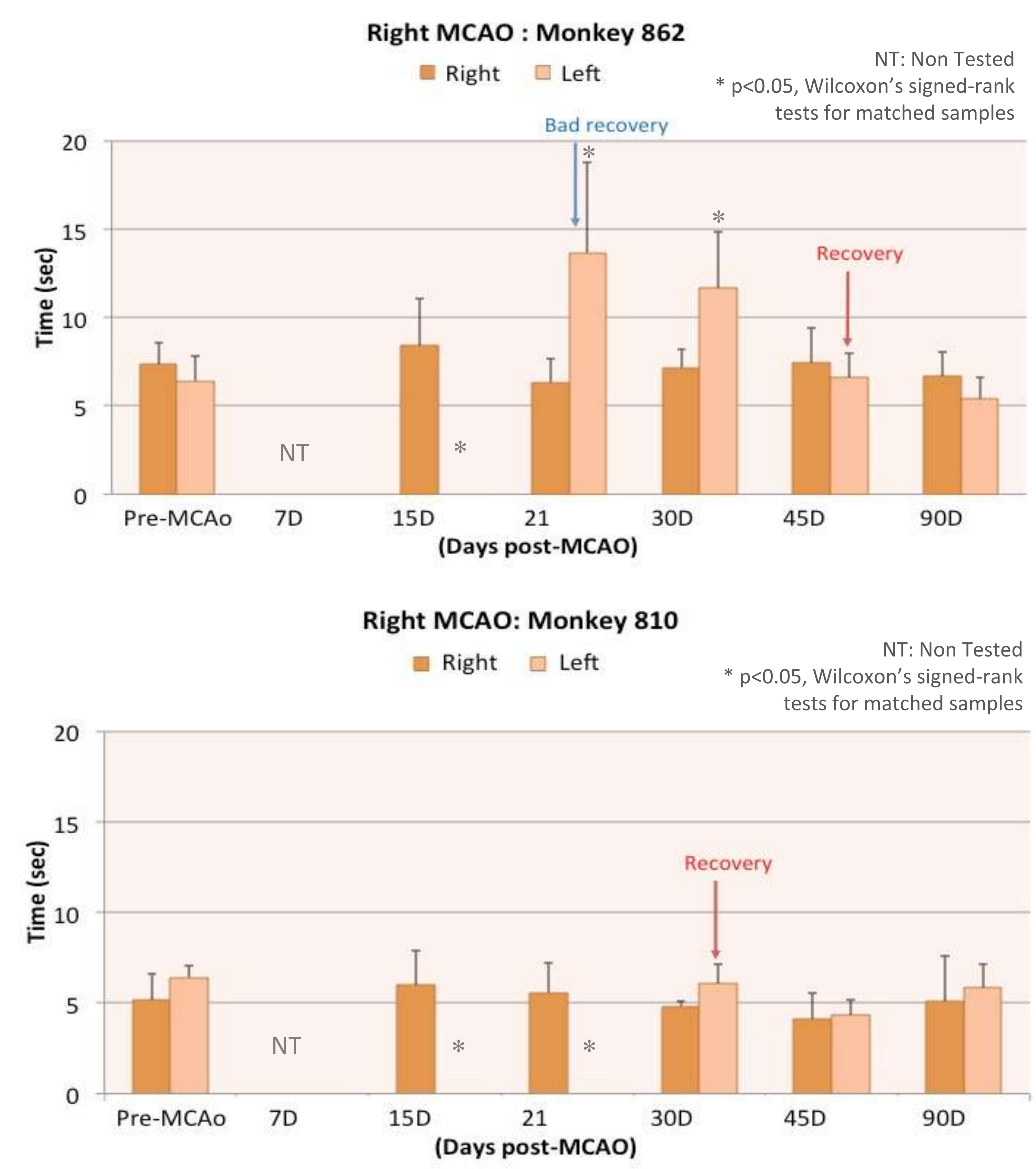

$\checkmark$ MRI analyses:
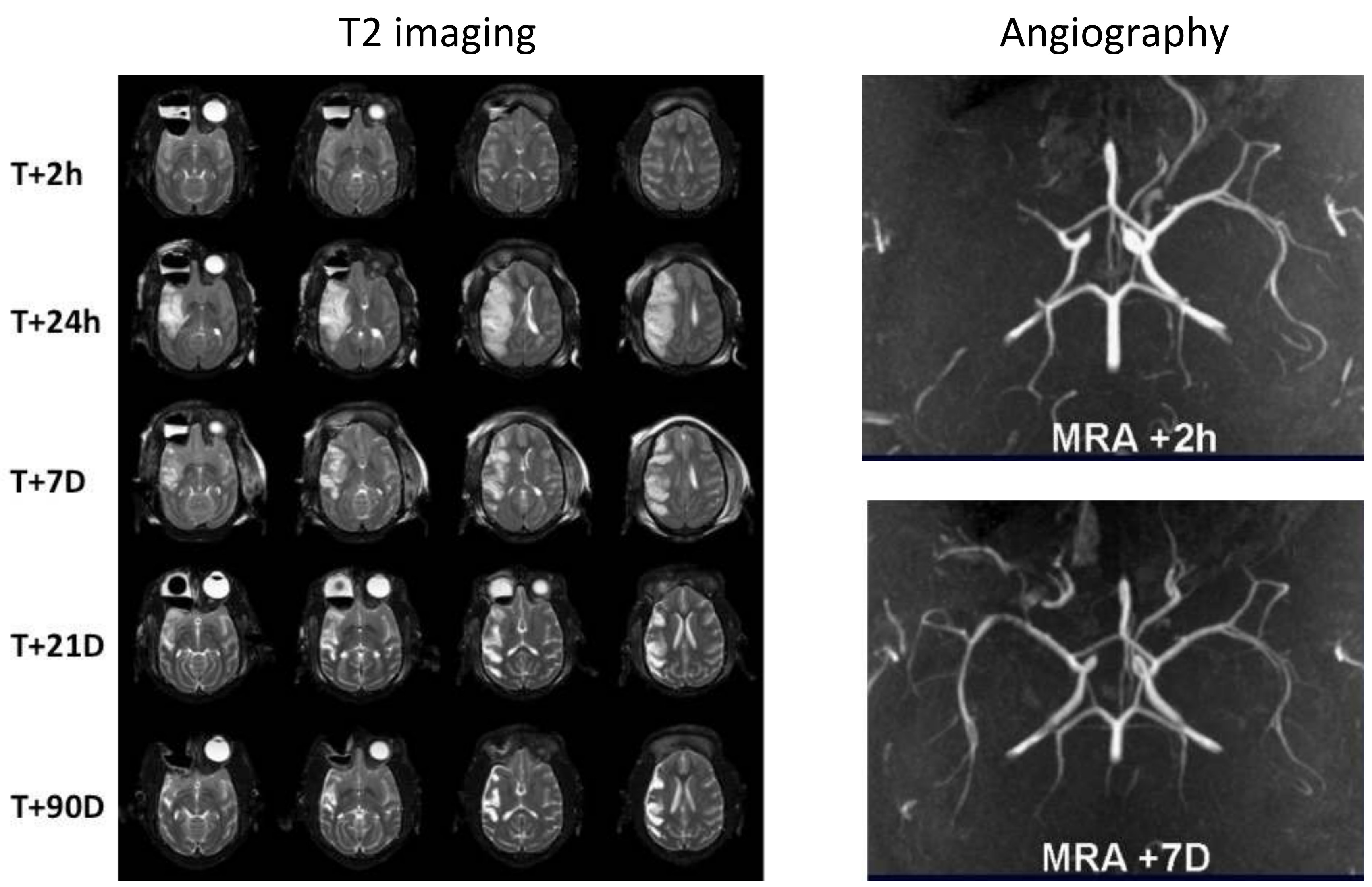

BBB permeability for gadolinium

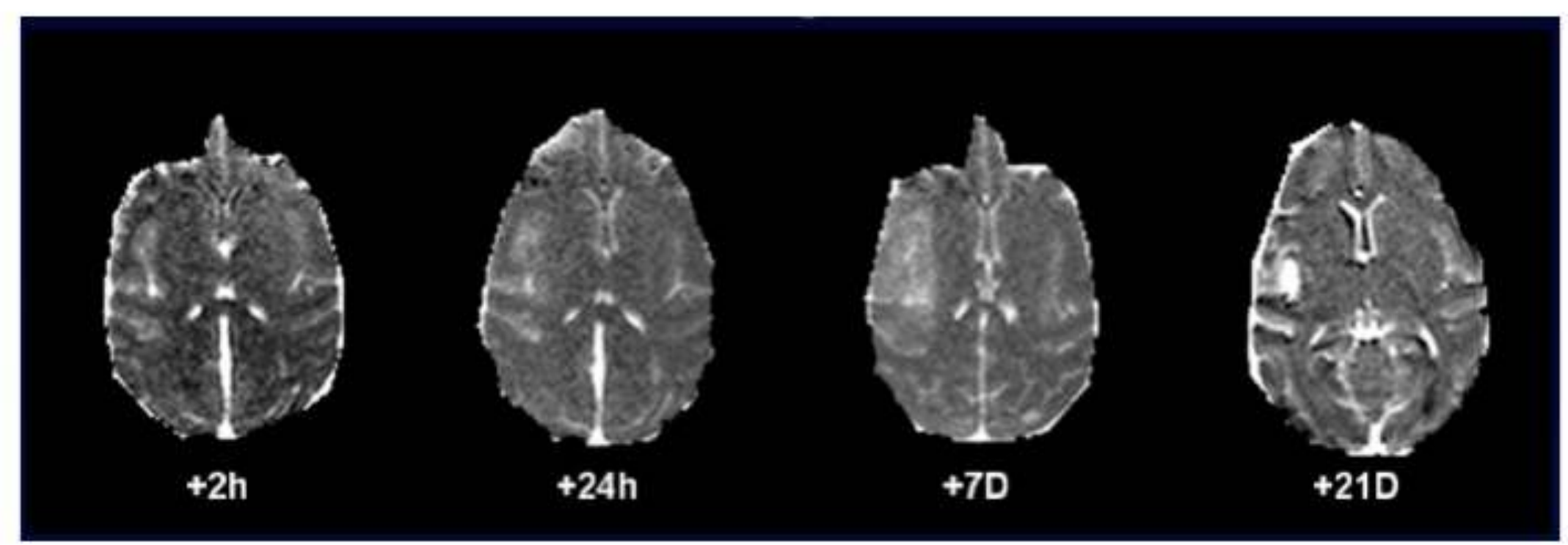

(T1 post-contrast) - (T1 pre-contrast)

\section{CONCLUSION}

$\checkmark$ We describe an original model of in situ clot formation in which imaging, physiological and functional analyses mimic human stroke evolution. In order to improve a similar model developed in mice (Orset et al., 2007), we provide here a non-human primate model of stroke which we consider to be more relevant to preclinical studies.

\section{ACKNOWLEDGEMENTS AND CONTACT}

$\checkmark$ The authors would like to thank Pauline Obiang and Pierre Guedin for their help.

For more information please contact : oceane.wateau@cynbiose.com 